PL, Messa P, Ravani P, Mosca M. Fetal outcome and recommendations of pregnancies in lupus nephritis in the 21 st century. A prospective multicenter study.J Autoimmun. 2016 Nov;74:6-12. doi: 10.1016/j.jaut.2016.07.010. Epub 2016 Aug 2.

Acknowledgements: We are grateful whit Secyt subsidy UNC.

Disclosure of Interest: None declared

DOI: 10.1136/annrheumdis-2017-eular.5621

\section{AB0486 INCIDENCE OF VERTEBRAL FRACTURES: 8 YEARS FOLLOW-UP STUDY IN WOMEN WITH SYSTEMIC LUPUS ERYTHEMATOSUS}

C. Mendoza Pinto ${ }^{1,2}$, M.D.L.L. Leon Vazquez ${ }^{3}$, A. Montiel Jarquin ${ }^{4}$, H. Sandoval-Cruz ${ }^{5}$, M.A. Buendía Luca ${ }^{1}$, M. García-Carrasco ${ }^{1,6} .{ }^{1}$ Medicine School, BUAP; ${ }^{2}$ Systemic Autoimmune Diseases Research, Hgr36-Cibior, IMSS; ${ }^{3}$ Systemic Autoimmune Diseases Research, Hgr-36 Imss; ${ }^{4}$ Hospital de Traumatología y Ortopedia, IMSS; ${ }^{5}$ Radiology Unit, Hgr-36 Imss; ${ }^{6}$ Systemic Autoimmune Disease Research Unit, Hgr36-Cibior, IMSS, Puebla, Mexico

Background: Vertebral fractures (VF) are the hallmark of bone fragility. Patients with systemic lupus erythematosus (SLE) are at high risk of developing prevalent VF. Although several risk factors for VF in patients with SLE have been suggested, there is limited longitudinal supporting data in the literature.

Objectives: The aims of this study are to determine the incidence of VF and to evaluate possible associations between potential risk factors and the occurrence of VF in women with SLE.

Methods: Consecutive patients with SLE were enrolled in a prospective, observational study from 2006 to 2015. Information on potential risk factors, including demographics, clinical data and bone mineral density (BMD) at the lumbar spine and hip on dual-energy X-ray absorptiometry was collected at baseline and follow-up. Semi-quantitative analysis was used to determine incident VF on lateral thoracic and lumbar radiographs, defined as any vertebral body graded normal at baseline and at least mildly deformed $(20-25 \%$ reduction or more in any vertebral height) during follow-up. Differences in baseline characteristics were assessed in patients with and without radiographic VF.

Statistical analysis: The Chi-square or Fisher's exact test, independent samples $\mathrm{t}$-test, and Mann-Whitney U-test were used as appropriate to compare baseline characteristics of patients with and without prevalent or incident VF. Possible risk factors for incident $\mathrm{VF}$ were assessed by multivariate logistic regression analysis. Results: Of 110 SLE patients included, with a median follow-up of 8 (IQR 8-9) years, $22(20 \%)$ had radiographic VF at baseline; $35(32 \%)$ patients had a new VF. The annual incidence rate of new morphometric VF was $3.5(95 \% \mathrm{Cl}$ 2.4-4.91) per 100 patient/years. Most fractures were located in the mid-thoracic and thoracolumbar region of the spine. Table 1 shows sociodemographic and clinical differences between patients with and without VF. In the multivariable analysis, VF were significantly associated with baseline BMD at the total hip and longer disease duration. Cumulative glucocorticoid dose, postmenopausal status and previous prevalent VF were not associated with VF.

\begin{tabular}{|c|c|c|c|}
\hline & \multicolumn{2}{|c|}{ Vertebral fractures } & \multirow[b]{2}{*}{$p$} \\
\hline & Yes $(n=35)$ & No $(\mathrm{n}=105)$ & \\
\hline Age, years, mean (SD) & $44.1 \pm 11.0$ & $41.4 \pm 11.8$ & 0.272 \\
\hline BMI, kg/m², mean (SD) & $27.1 \pm 5.3$ & $27.3 \pm 3.9$ & 0.871 \\
\hline Postmenopausal at baseline, n (\%) & $22(63)$ & $30(40)$ & 0.021 \\
\hline Disease duration, years, median (IQR) & $9.0(5 \cdot 14)$ & $5.0(3 \cdot 12)$ & 0.005 \\
\hline Vertebral deformity at bascline, n (\%) & $9(26)$ & $13(17)$ & 0.317 \\
\hline $25 \mathrm{OHvitD}$ kvels, ng/mL, mxan (SD) & $20.8 \pm 6.6$ & $19.1 \pm 7.0$ & 0.407 \\
\hline SLICC/ACR DI, 21 n (\%) & $21(60)$ & $29(39)$ & 0.042 \\
\hline $\begin{array}{l}\text { Cumulative dose of GCT, gram, median } \\
\text { (IQR) }\end{array}$ & $16.2(7.41)$ & $9.9(6.24)$ & 0.037 \\
\hline BMD lumbar spinc, $g / \mathrm{cm}^{2}, \operatorname{mean}(\mathrm{SD})$ & $0.981 \pm 0.222$ & $1.039 \pm 0.217$ & 0.205 \\
\hline BMD total hip, $\mathrm{g} / \mathrm{cm}^{2}$, median (IQR) & $0.884(0.844-1.025)$ & $0.981(0.914-1.055)$ & 0.011 \\
\hline Use of bisphosphonates during follow-up. & $15(43)$ & $24(32)$ & 0.185 \\
\hline
\end{tabular}

Conclusions: In this SLE cohort in daily clinical practice, radiographic VF were frequently present in SLE patients, especially those with longer disease duration and low hip BMD.

\section{References:}

[1] Borba VZC, Matos PG, da Silva Viana PR, et al. High prevalence of vertebral deformity in premenopausal systemic lupus erythematosus patients. Lupus. 2005;14(7):529-33.

[2] Mendoza-Pinto C, García-Carrasco M, Sandoval-Cruz H, et al. Risk factors of vertebral fractures in women with systemic lupus erythematosus. Clin Rheumatol. 2009;28(5):579-85.

[3] Bultink IEM, Lems WF, Kostense PJ, et al. Prevalence of and risk factors for low bone mineral density and vertebral fractures in patients with systemic lupus erythematosus. Arthritis Rheum. 2005;52(7):2044-50.
Acknowledgements: This work was supported in part by grant from FIS/IMSS/PROT/MD15/1500

Disclosure of Interest: None declared

DOI: 10.1136/annrheumdis-2017-eular.1238

\section{AB0487 NEUROLOGIC MANIFESTATIONS AND THEIR IMPACT ON CHRONIC DAMAGE IN PATIENTS WITH ANTIPHOSPHOLIPID SYNDROME: RESULT FROM A MONOCENTRIC COHORT}

D. Mazilu $^{1}$, D. Potarniche ${ }^{2}$, I. Saulescu ${ }^{1}$, A. Borangiu ${ }^{1}$, L. Groseanu ${ }^{1}$, C. Constantinescu ${ }^{1}$, V. Vlad ${ }^{2}$, F. Berghea ${ }^{1}$, V. Bojinca ${ }^{1}$, D. Opris-Belinski ${ }^{1}$, A. Balanescu ${ }^{1}$, D. Predeteanu ${ }^{1}$, R. Ionescu ${ }^{1}$. " "Sfanta Maria" Clinical Hospital, "Carol Davila" University of Medicine, Bucharest, Romania; "Sfanta Maria" Clinical Hospital, Bucharest, Romania

Background: Antiphospholipid syndrome (APS) is an autoimmune disease with wide clinical features and cumulative damage. The nervous system involvement is very broad and severe.

Objectives: The aim of this study is to analyze the impact of neurologic manifestations on Damage Index in Patients with APS (DIAPS).

Methods: All consecutive patients known with APS were included in our monocentric cohort. Data on medical history, clinical manifestations, aPL profile and medication were collected. DIAPS score was used to measure damage in each patient.

Results: Seventy six patients with APS were included: 11 patients with primary APS and 65 patients with secondary APS, with mean disease duration of $9.59 \pm 7.39$ years. Overall, 35 patients $(46.1 \%)$ had neurologic manifestations. Their mean disease duration was $9.2 \pm 5.76$ years. Seven patients had primary APS and 28 patients had secondary APS. Six patients were on chronic oral anticoagulant therapy and low dose aspirin, 12 patients on oral anticoagulant alone and 15 patients on low dose aspirin. Transient ischemic attack was the first manifestation of APS in 4 patients $(11.42 \%)$ at mean age of $29.5 \pm 10.96$ years. Their mean DIAPS value was $7.75 \pm 4.19$. Ischemic stroke was the first APS manifestation in 12 patients $(34.28 \%)$ at mean age of $40.08 \pm 16.31$ years, with DIAPS mean value of $7.41 \pm 3.67$. All of these patients have neurological sequelaes. The DIAPS value was higher in patients with neurologic manifestations ( $3 \pm 2.9$ vs $5.71 \pm 3.62$, $\mathrm{p}=0.001$ ) and DIAPS value correlated significantly to neurologic manifestations $(R=0.416, p<0.000)$ reflecting it's impact on cumulative damage in APS patients. Conclusions: Neurologic manifestations in APS patients have a great impact on cumulative damage especially in patients presenting with ischemic stroke or transient ischemic attack as the first manifestation of APS.

References:

[1] M-C Amigo et al. Development and initial validation of a damage index (DIAPS) in patients with thrombotic antiphospholipid syndrome (APS). Lupus (2015) 24, 927-934.

[2] L.A. Martinez-Martinez et al. Damage Index in Patients with Thrombotic Antiphospholipid Syndrome: Retrospective Cohort Study. Ann Rheum Dis 2016;75:1065.

Disclosure of Interest: None declared

DOI: 10.1136/annrheumdis-2017-eular.4370

\section{AB0488 CAPILLAROSCOPY FINDINGS IN CHILDHOOD-ONSET SYSTEMIC LUPUS ERYTHEMATOSUS, A DUTCH EXPERIENCE OF 20 CHILDREN AND ADOLESCENTS}

D. Schonenberg-Meinema ${ }^{1}$, M. vd Berg ${ }^{1}$, A. Nassar-Sheikh-Rashid ${ }^{1}$, G. de Bree $^{2}$, L. Hak ${ }^{3}$, M. van Onna ${ }^{3}$, K. Melsens ${ }^{4,5}$, M. Cutolo ${ }^{6}$, T. Kuijpers ${ }^{1}$, V. Smith ${ }^{4,5}$. ${ }^{1}$ Department of Pediatric Hematology, Immunology, Rheumatology and Infectious Diseases; ${ }^{2}$ Department of Infectious Diseases; ${ }^{3}$ Department of Clinical Immunology and Rheumatology, AMC Amsterdam, Amsterdam, Netherlands; ${ }^{4}$ Department of Rheumatology; ${ }^{5}$ Department of Internal Medicine, Ghent University Hospital, Ghent, Belgium; ${ }^{6}$ Research Laboratory and Academic Unit of Clinical Rheumatology, University of Genova, Genova, Italy

Background: Capillaroscopy findings can be qualitatively described as: normal, microangiopathy (non-specific abnormalities) or scleroderma pattern (1). Capillary abnormalities, described in varying prevalence in patients with systemic lupus erythematosus (SLE), are mainly described as microangiopathy (2-4)

Objectives: To describe capillary characteristics in a cross-sectional cohort of patients with childhood-onset SLE (CSLE) by quantitative and qualitative assessment

Methods: Nailfold videocapillaroscopy (NVC) was performed in cSLE-patients (onset $<18$ years) with a $\times 200$ magnification lens (Optilia). The following capillaroscopic characteristics were evaluated per millimeter: density (compared to mean density known for age, sex and ethnicity) (5), number of abnormal shapes (as defined by the EULAR study group on microcirculation in Rheumatic Diseases (6)), giant capillaries (defined as apical diameter $>50 \mathrm{mcm}$ ), maximum apical diameter (dilatations defined as apical diameter $20-50 \mathrm{mcm}$ ) and microbleedings (large hemorrhages and small multiple point-shaped hemorrhages surrounding the capillary loop [image])

Results: 4063 capillaries from 20 patients with cSLE, were analyzed. All patients showed capillary abnormalities, $15 \%(n=3)$ showed a scleroderma-pattern. A lower mean density (mean 6.7, range 1.9-9.5) was seen in $55 \%(n=11)$, multiple 
( $>8$ per patient) abnormal shapes in $60 \%(n=12)$, apical dilatations in $90 \%(n=18)$. Total count of large/small point shaped hemorrhages was 109/855, with a mean of $0.2 / 1.6$ per analyzed image/per patient. These were detected in $85 / 85 \%$ of patients $(n=17)$

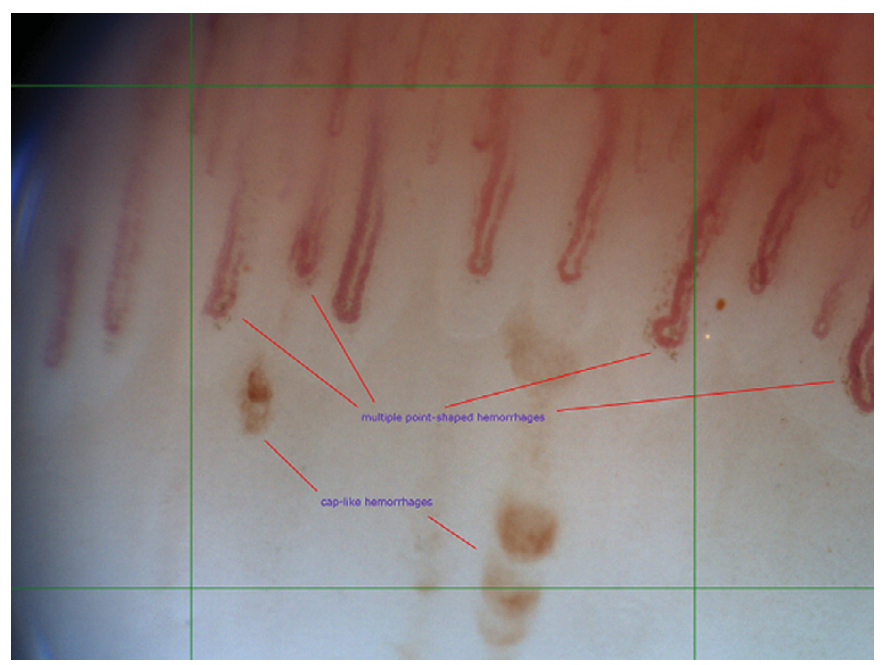

Conclusions: In this pilot $(n=20)$ of cSLE patients, all showed capillary abnormalities. The most striking finding was the point-shaped bleeding surrounding the capillary, observed in $85 \%(n=17)$ of our patients. Prospective longitudinal cohort studies in children through the EULAR study group on microcirculation in Rheumatic diseases will elucidate whether specific findings can be found in child rheumatic diseases

References:

[1] Cutolo M. Atlas of capillaroscopy in rheumatic diseases. Milan: Elsevier; 2010.

[2] Ingegnoli F. Capillaroscopy abnormalities in relation to disease activity in juvenile systemic lupus erythematosus. Microvascular research. 2013;87:924

[3] Dolezalova P, Young SP, Bacon PA, Southwood TR. Nailfold capillary microscopy in healthy children and in childhood rheumatic diseases: a prospective single blind observational study. Ann Rheum Dis. 2003;62(5):4449 .

[4] Shenavandeh S, Habibi S. Nailfold capillaroscopic changes in patients with systemic lupus erythematosus: correlations with disease activity, skin manifestation and nephritis. Lupus 2017:961203316686702.

[5] Terreri MT, Andrade LE, Puccinelli ML, Hilario MO, Goldenberg J. Nail fold capillaroscopy: normal findings in children and adolescents. Seminars in arthritis and rheumatism. 1999;29(1):36-42.

[6] Smith V, Beeckman S, Herrick AL, Decuman S, Deschepper E, De Keyser $\mathrm{F}$, et al. An EULAR study group pilot study on reliability of simple capillaroscopic definitions to describe capillary morphology in rheumatic diseases. Rheumatology (Oxford). 2016;55(5):883-90.

Disclosure of Interest: None declared

DOI: 10.1136/annrheumdis-2017-eular.4704

\section{AB0489 THE SLE-KEY ${ }^{\circledR}$ RULE-OUT TEST PERFORMS WELL AS AN AID IN CLINICAL PRACTICE}

D. Massenburg, J. Oldenberg, A. Sell, T. Krause, A.F. Wells. Rheumatology and Immunotherapy Center, Franklin, WI, United States

Background: The SLE-key ${ }^{\circledR}$ test was developed by ImmunArray and was validated to rule out SLE with $94 \%$ sensitivity, $75 \%$ specificity and a negative predictive value (NPV) of $93 \%{ }^{1}$. We reported earlier that the SLE-key ${ }^{\circledR}$ RuleOut test could aid in the diagnosis and disposition of a cohort of 55 patients in our clinical practice 2

Objectives: We have now expanded this cohort and report here the usefulness of the SLE-key ${ }^{\circledR}$ test in aiding the management of a cohort of challenging and suspected SLE patients in a large clinical practice.

Methods: In patients referred to the Rheumatology and Immunotherapy Center, in Franklin, WI, results from the SLE-key ${ }^{\circledR}$ RuleOut test were included as part of the clinical evaluation. Serum samples were collected from individual subjects with informed consent and tested at VERACIS (Richmond, VA), using the SLE-Key ${ }^{\circledR}$ iCHIP ${ }^{\circledR 1}$.

Results: We reviewed the diagnoses and clinical disposition of patients both before and after SLE-key ${ }^{\circledR}$ testing. In particular, we looked at the ability of the SLE-key ${ }^{\circledR}$ test to enhance our ability to reach a definitive diagnosis across the full cohort of patients, at the disposition of patients who were referred with a suspicion of SLE as part of the differential diagnosis, at the impact of SLE-key ${ }^{\circledR}$ testing on the diagnosis of the subset of patients who presented with minimal symptoms, and at the group of patients who had been referred following an ANA test. Results are summarized in Table 1. In the cases where SLE was ruled out, patients were treated for a variety of disorders including fibromyalgia, joint pain, MCTD, Sjogren's disease and others.

Table 1

\begin{tabular}{|c|c|c|}
\hline Patient Subgroup & Status post SLE-key & Clinical Outcomes \\
\hline $\begin{array}{l}\text { Patients with uncertain } \\
\text { diagnosis in our clinic prior to } \\
\text { SLE-key }{ }^{\circledR} \text { testing. }\end{array}$ & $\begin{array}{l}79 \% \text { had an actionable } \\
\text { diagnosis following SLE-key }{ }^{\circledR} \\
\text { test }\end{array}$ & $\begin{array}{l}57 \% \text { were diagnosed to have } \\
\text { SLE. } 43 \% \text { not SLE. Patients } \\
\text { treated for a variety of } \\
\text { disorders other than SLE }\end{array}$ \\
\hline $\begin{array}{l}\text { Patients referred to our clinic } \\
\text { with SLE as part of differential } \\
\text { diagnosis }\end{array}$ & $\begin{array}{l}62 \% \text { confirmed SLE } 32 \% \\
\text { Ruled Out }\end{array}$ & $\begin{array}{l}>50 \% \text { of those RuledOut were } \\
\text { diagnosed with myalgia/ } \\
\text { fibromyalgia and treated } \\
\text { accordingly }\end{array}$ \\
\hline $\begin{array}{l}\text { Minimally symptomatic } \\
\text { patients }\end{array}$ & $65 \%$ Ruled Out for SLE & $\begin{array}{l}\text { Patients treated for a variety of } \\
\text { disorders other than SLE }\end{array}$ \\
\hline $\begin{array}{l}\text { Patients referred following } \\
\text { ANA testing }\end{array}$ & $44 \%$ Ruled Out for SLE & $\begin{array}{l}\text { Patients treated for a variety of } \\
\text { disorders other than SLE }\end{array}$ \\
\hline
\end{tabular}

Conclusions: The diagnosis of patients referred in the clinical rheumatology setting remains an ongoing challenge. The SLE-key ${ }^{\circledR}$ RuleOut test provides a laboratory aid to improve the diagnostic and dispositive efficiency saving undue concern, time and resources both to the patient and to the healthcare system. A retrospective analysis of our practices prior to the introduction of SLE-key ${ }^{\circledR}$ is warranted.

References:

[1] Putterman et al., Journal of Immunological Methods, 2016.

[2] Massenburg et al., Arthritis Rheumatol. 2016; 68 (suppl 10).

Disclosure of Interest: None declared

DOI: 10.1136/annrheumdis-2017-eular.5779

\section{AB0490 ANALYSIS OF COMMON GRAM-NEGATIVE BACTERIA AND THEIR DRUG RESISTANCE IN HOSPITALIZED PATIENTS WITH SYSTEMIC LUPUS ERYTHEMATOSUS}

D. Chen, Z. Zhan. Rheumatology, The first affiliated hospital of SUN YAT-SEN UNIVERSITY, Guangzhou, China

Background: Infection is an important cause of morbidity and mortality in patients with systemic lupus erythematosus (SLE). The spectrum of infectious agents in SLE patients varies significantly among different ethnic groups. The national surveillance study from the China showed that Gram-negative bacteria (GNB) was the most the common bacterial infection in China, while Gram-positive bacteria (GPB) was predominant in European countries.

Objectives: To identify the spectrum and drug resistant pattern of infection caused by GNB in patients hospitalized with SLE.

Methods: The clinical and microbiological data from hospitalized SLE patients with bacterial infection between June 2005 and June 2015 was collected and then analyzed retrospectively.

Results: Two hundred and sixty-eight episodes of bacteria had been identified from 3815 hospitalized patients. In terms of isolated microorganisms, gramnegative bacteria (GNB) were predominant over gram-positive bacteria (GPB) (178 isolates vs. 90 isolates). In the GNB, Escherichia coli $(66 / 178,37.1 \%$ ) was the most common isolate, followed by Acinetobacter baumannii $(36 / 178$, $20.2 \%)$, Klebsiella pneumoniae (24/178, 13.5\%), Pseudomonas aeruginosa $(20 / 178,11.2 \%)$, Haemophilus influenzae $(10 / 178,5.6 \%)$, Salmonella sp. $(7 / 178$, $3.9 \%)$, Enterobacter aerogenes $(5 / 178,2.8 \%)$, Stenotrophomonas maltophilia $(5 / 178,2.8 \%)$, Citrobacter freundii $(3 / 178,1.7 \%)$, Proteus mirabilis $(2 / 178,1.1 \%)$. Resistant isolates $(53 / 178,30.0 \%)$ were more common documented in GNB, mostly extended-spectrum beta-lactamase (ESBL) producing Escherichia coli $(30 / 66,45.5 \%)$ and Klebsiella pneumonia (6/24, 25\%), and multi-drug resistant acinetobacter baumannii $(36.1 \%)$. Susceptibility tests showed that the ESBLproducing strains were highly sensitive to carbapenems, $\beta$-lactamase inhibitor compound families, and certain cefalosporin (Cefepime and Ceftazidime) in vitro (the resistance rate $<20 \%$ ), whereas it was highly resistant to ampicillin and Gentamicin. Besides carbapenems and Cefoperazone/sulbactam, Acinetobacter baumannii was resistant to most antibiotics.

Conclusions: GNB was predominant in Chinese hospitalized patients with SLE. The drug resistance of GNB has increased significantly. It was necessary to rational use of antibiotics in patients with SLE.

Disclosure of Interest: None declared

DOI: 10.1136/annrheumdis-2017-eular.1951

\section{AB0491 THE ASSOCIATION OF BASELINE HYPERURICEMIA IN PREMENOPAUSAL WOMEN WITH SYSTEMIC LUPUS ERYTHEMATOSUS AND DEVELOPMENT OF NEPHRITIS}

D.H. Lim ${ }^{1}$, S. Hong ${ }^{2}$, J.S. Oh ${ }^{3}$, Y.-G. Kim ${ }^{2}$, C.-K. Lee ${ }^{2}$, S.W. Choi ${ }^{1}$, B. Yoo ${ }^{2}$. ${ }^{1}$ Division of rheumatology, Department of Internal Medicine, Ulsan university hospital, Ulsan; ${ }^{2}$ Division of rheumatology, Department of Internal Medicine, Asan Medical Center; ${ }^{3}$ Division of rheumatology, Department of Internal Medicine, National Medical Center, Seoul, Korea, Republic Of

Background: Renal involvement is a common and serious manifestation of SLE. Hyperuricemia may be associated with lupus nephritis as a result of renal 